\title{
Factors Associated With Sarcopenia Screened by Finger-Circle Test Among Middle-Aged and Older Adults: A Population-Based Multisite Cross-Sectional Survey in Japan
}

\author{
Daiki Watanabe ( $\nabla$ d2watanabe@nibiohn.go.jp) \\ National Institute of Biomedical Innovation, Health and Nutrition \\ Tsukasa Yoshida \\ National Institute of Biomedical Innovation, Health and Nutrition \\ Takashi Nakagata \\ National Institute of Biomedical Innovation, Health and Nutrition \\ Naomi Sawada \\ Settsu city local Government \\ Yosuke Yamada \\ National Institute of Biomedical Innovation, Health and Nutrition \\ Kayo Kurotani \\ Showa Women's University \\ Kenji Tanaka \\ Hannan city local Government \\ Megumi Okabayashi \\ Osaka Prefectural Government \\ Hidekazu Shimada \\ Osaka Prefectural Government \\ Hidemi Takimoto \\ National Institute of Biomedical Innovation, Health and Nutrition \\ Nobuo Nishi \\ National Institute of Biomedical Innovation, Health and Nutrition \\ Keiichi Abe \\ National Institute of Biomedical Innovation, Health and Nutrition \\ Motohiko Miyachi \\ National Institute of Biomedical Innovation, Health and Nutrition
}

\section{Research Article}

Keywords: sarcopenia, random cluster sampling, middle-aged and older adults, finger-circle (yubi-wakka) test, multisite cross-sectional survey

Posted Date: January 4th, 2021

DOI: https://doi.org/10.21203/rs.3.rs-135859/v1

License: (a) This work is licensed under a Creative Commons Attribution 4.0 International License. Read Full License

Version of Record: A version of this preprint was published at BMC Public Health on April 26th, 2021. See the published version at https://doi.org/10.1186/s12889-021-10844-3. 


\section{Abstract}

Background: Prior epidemiological studies have demonstrated the prevalence and the relationship of various factors associated with sarcopenia in older adults; however, few have examined sarcopenia status in middle-aged adults. In the present study, we aimed: 1) to evaluate the validity of the finger-circle test, which is potentially a useful screening tool, for assessing sarcopenia, and 2) to determine the prevalence and factors associated with sarcopenia in middle-aged and older adults.

Methods: We conducted a face-to-face survey with 525 adults aged 40-91 years residing in Settsu City, Osaka Prefecture, Japan to evaluate the validity of finger-circle test. The finger-circle test was evaluated calf circumference by referring to an illustration printed on the survey form. To assess sarcopenia, the area under the receiver operating characteristic curves (AUROC) was plotted to evaluate the validity of the finger-circle test compared to sarcopenia evaluation by skeletal muscle mass index (SMI) measured using bioimpedance. We also conducted a multisite population-based cross-sectional anonymous mail surveys of 9337 adults aged 40-97 years residing in Settsu and Hannan Cities, Osaka Prefecture, Japan. Participants were selected through stratified random sampling by sex and age group, in the elementary school zones of their respective cities. We performed multiple logistic regression analysis to explore associations between characteristics and prevalence of sarcopenia.

Results: Sarcopenia, defined by SMI, was moderately predicted by a finger-circle test response showing that the subject's calf was smaller than their finger-circle (AUROC: $0.729,<65$ years; $0.653, \geq 65$ years); such subjects were considered to have sarcopenia. In mail surveys, prevalence of sarcopenia was higher in older subjects (approximately $16 \%$ ) than in middle-aged subjects (approximately $8-9 \%$ ). In a multiple regression model, the factors associated with sarcopenia were age, body mass index, smoking status, self-reported health, and number of meals in all the participants.

Conclusions: Sarcopenia, screened by the finger-circle test, was present not only among older adults but also among middle-aged adults. These results suggest the importance of providing middle-aged and older adults with the opportunity to individually perform a test that could enable them to identify sarcopenia.

Trial registration: UMIN000008105, registered prospectively May 29, 2019, https://upload.umin.ac.jp/cgi-open-bin/ctr_e/ctr_view.cgi? recptno=R000042027

\section{Background}

Sarcopenia, a syndrome characterized by reduced physical function associated with the loss of skeletal muscle mass and strength [1-4], is associated with adverse health outcomes, such as increased mortality [5, 6] and disabilities [7], among community-dwelling adults aged $\geq 65$ years. In 2016, sarcopenia was recognized as a disease in the International Classification of Diseases-10 [8]. In addition, sarcopenia is reportedly associated with the risk of mortality in patients with nonmetastatic breast cancer [9]. Therefore, reducing the number of patients with sarcopenia is important from a public health perspective, to extend healthy lifespans, and from a clinical perspective, to reduce healthcare and nursing care expenses [10]. Determining the prevalence of sarcopenia and its associated factors is essential for establishing an effective sarcopenia prevention program.

Calf circumference is strongly associated with appendicular skeletal muscle mass (ALM) in middle-aged and older adults [11-13]. The Asian Working Group for Sarcopenia (AWGS) 2019 Consensus developed a set of guidelines for diagnosing and treating sarcopenia in Asians and proposed the calf circumference as a sarcopenia screening tool [2]. Subsequently, the need for a simple approach than the calf circumference led to the development of the finger-circle (yubi-wakka) test, which can be conducted by the subjects using their own fingers and does not require any special devices [14, 15]. This test is reportedly associated with psoas muscle mass [15], sarcopenia [14], and the risk of mortality [14] among older adults. Therefore, the finger-circle test could serve as an effective sarcopenia screening tool.

Studies among community-dwelling older adults have reported that factors such as age [16-20], sex [16, 19, 21], body mass index (BMI) [16$18,20]$, smoking status [22], and chronic conditions [16, 18, 19,23] are associated with the prevalence of sarcopenia. However, since these studies were on older adults, little is known about the developmental status of sarcopenia in middle-aged adults. In addition, due to the low statistical power of small sample sizes, studies that randomly sample large populations to explore factors associated with sarcopenia are needed. To the best of our knowledge, the prevalence and factors associated with sarcopenia in middle-aged and older Japanese adults have not yet been determined. The life-style intervention program can reduce the progression of functional decline among older adults with moderate physical disorder but not those with severe physical disorder [24]. Therefore, identifying these associations is essential for early detection and prevention of sarcopenia in those aged 30 years and above, when the muscle mass and strength begin to decline [25]. In this study, we aimed 1) to evaluate the validity of the finger-circle test for detecting sarcopenia, in a face-to-face survey and 2) to determine the 
prevalence and factors associated with sarcopenia among randomly selected middle-aged and older adults, based on the demographic ratios of sex and age group in the general populations of Settsu and Hannan Cities, Osaka Prefecture, Japan.

\section{Methods}

\section{Study population}

From July 1 to July 9, 2019, we conducted a face-to-face survey including men and women aged $\geq 40$ years residing in Settsu City. These participants were recruited either when they participated in a specific health examination conducted at the Settsu Health Center or via Settsu's public relations magazine (Fig. 1). We assessed the validity of the finger-circle test for assessing sarcopenia by comparing the test data obtained from participants aged 40-91 years with their body composition-based assessment data $(n=525)$.

The present study is a multisite population-based cross-sectional anonymous mail survey of men and women aged $\geq 40$ years residing in the cities of Settsu and Hannan in Osaka Prefecture, Japan. Settsu is a municipality in Mishima District (population: 85007; area: 14.87 km²) in northern Osaka Prefecture [26], while Hannan is a municipality in Sennan District in southern Osaka Prefecture (population: 54276; area: $36.17 \mathrm{~km}^{2}$ ) [26]. Settsu and Hannan have 10 and 8 elementary school zones, respectively. To obtain a representative sample of the general population, we randomly selected 1000 subjects aged $\geq 40$ years stratified by sex and age group from each school zone (Fig. 1). Survey forms and envelopes were color-coded by school zone to identify each school zone respondents when their survey forms were returned. The Settsu mail survey was conducted from February 22, 2019 to March 5, 2019. Although 4502 survey forms were returned by March 7, 2019, additional 1,307 forms that were returned after that date were also included in the analysis (response rate: $58.1 \%$ ). The Hannan mail survey was conducted from January 20, 2020 to February 7, 2020. Survey forms were included only if they arrived by February 13, 2020 (response rate: $60.0 \%$ ). For both surveys, we sent a reminder postcard one week prior to the end of the survey period.

Of these participants, we excluded those with missing data on finger-circle test, age, or sex, and those who had a self-reported "needed longterm care" or "needed support". Ultimately, we included 9337 participants to this study.

\section{Survey content}

In the Settsu and Hannan mail surveys, we collected the following basic characteristics: age (years); sex (male or female); certification of needed support or long-term care (none, needed support level 1-2, needed long-term care level 1-5); height (centimeters); body weight (kilograms); drinking status ("Do you drink alcohol?": almost daily, sometimes, almost never, never); smoking status ("Do you smoke?": almost daily; sometimes; used to, but quit; never); living status ("Do you live alone?": yes, no); socioeconomic status ("Economically, how does your life feel currently?": hard, somewhat hard, somewhat easy, easy); self-reported health ("How healthy do you normally feel?": very healthy, somewhat healthy, not very healthy, unhealthy); self-reported physical fitness ("How confident are you in your current physical fitness?": extremely confident, somewhat confident, slightly anxious, very anxious); exercise habits ("Do you go walking or engage in other exercise at least once per week?": yes, no); mastication function ("Is it more difficult for you to eat hard foods now than it was six months ago?": yes, no); number of meals ("How many meals do you eat per day (excluding snacks)?": [number of meals]); sleep status ("In the past month, have you been getting enough rest from sleep?": yes, somewhat, not very much, not at all); short-term cognitive ability ("Can you remember what happened 5 minutes ago?": yes, no); and gait speed ("Do you feel like your gait speed is slower than it used to be?": yes, no). BMI was calculated as body weight $(\mathrm{kg})$ divided by the square of height $(\mathrm{m})$.

\section{Definition of sarcopenia}

In the face-to-face survey, height was measured in $0.1 \mathrm{~cm}$ increments using a stadiometer with the participants' shoes removed. Body composition was assessed via bioimpedance (MC-780A, TANITA Corp., Tokyo, Japan) with participants wearing as light clothing as possible [27]. Sarcopenia was defined by a skeletal muscle mass index (SMI) (evaluated by the bioimpedance method) of $<7.0 \mathrm{~kg} / \mathrm{m}^{2}$ in men and $<5.7$ $\mathrm{kg} / \mathrm{m}^{2}$ in women, in accordance with the AWGS 2019 Consensus [2]. SMI was calculated as the ALM ( $\mathrm{kg}$ ) divided by the square of the height $\left(\mathrm{m}^{2}\right)$.

In the mail survey, sarcopenia was assessed by the self-reported finger-circle test, that was validated in adults aged $\geq 65$ years $[14,15]$. The finger-circle (yubi-wakka) test determines whether the circumference of a participant's finger, formed by their index fingers and thumbs, is smaller than the participant's maximum non-dominant calf circumference. This test is explained in detail elsewhere [14, 15]. By referring to an illustration printed on the survey form, we asked the participants to conduct the finger-circle test according to the following instructions (Fig. 2): "Put your two index fingers together and your two thumbs together to make a circle around your calf. Compare the size of this fingercircle to the thickness (circumference) of the thickest part of your calf (calf is smaller [smaller], calf and finger-circle are about the same size 
[same size], or calf is bigger [bigger])." A prospective cohort study revealed an association between the finger-circle test outcomes and sarcopenia and mortality risks in adults aged $\geq 65$ years [14].

\section{Statistical analysis}

Settsu and Hannan mail survey data were analyzed separately. Continuous and ordinal participant characteristics were classified for: age (40-49, 50-59, 60-69, 70-79, and 80 years); BMI (<18.5, 18.0-24.9, 25.0-29.9, and $\left.\geq 30.0 \mathrm{~kg} / \mathrm{m}^{2}\right)$; alcohol consumption ("almost daily," "sometimes," or "almost never" = alcohol drinkers and "never" = non-drinkers); smoking ("almost daily" or "sometimes" = current smokers, "used to, but quit" = past smokers, and "never" = never-smokers); socioeconomic status ("easy" or "somewhat easy" = high socioeconomic status, and "somewhat hard" or "hard" = low socioeconomic status); self-reported health ("very healthy" or "somewhat healthy" = good selfreported health, and "not very healthy" or "unhealthy" = poor self-reported health); self-reported physical fitness ("extremely confident" or "somewhat confident" = good self-reported physical fitness, and "slightly anxious" or "very anxious" = poor self-reported physical fitness); number of meals $(\geq 3,2$, and 1 meal); sleep status ("yes" and "somewhat" = good sleep status, while "not very much" and "not at all" = poor sleep status). Participant characteristics were described for the variables mentioned above. Continuous variables are shown as means and standard deviations, while categorical variables are shown as numbers and percentages. Missing values for these variables were created from five datasets by multiple imputation by chained equation [28]. All missing values were assumed to be missing at random. In addition, complete cases (cases with no missing values) and cases with missing values were compared by age, sex, and prevalence of sarcopenia.

In the face-to-face survey, height, and body composition data for each group of finger-circle test responses (bigger, same size, smaller) are shown as means and standard deviations. The $p$-values for linear trends were calculated by reporting the finger-circle test (the exposure variable) as a continuous variable. To examine the validity of the finger-circle test in assessing sarcopenia, we calculated the area under the receiver operating characteristic curves (AUROC) for the finger-circle test in relation to sarcopenia defined using SMI (the direct measurement). Previous studies verified the validity of the finger-circle test only in adults aged $\geq 65$ years $[14,15]$. Therefore, in our analyses, we stratified the participants by age ( $\geq 65$ or $<65$ years) and sex (male or female).

Prevalence of sarcopenia was reported as number of cases and percentages for the participants in the mail survey. To adjust for the distribution ratio of the sample in the mail survey participants to the distribution ratio of Settsu and Hannan populations, we calculated the prevalence of sarcopenia weighted by the distribution ratios according to age $(40-49,50-59,60-69,70-79$, and $\geq 80$ years) and sex (male or female) in each school zone [29]. We used the chi-square test to compare characteristics between the sarcopenia and non-sarcopenia groups.

We used multiple logistic regression analysis to examine factors associated with the prevalence of sarcopenia in the mail survey participants. In our multivariate analysis, the dependent variable was the prevalence of sarcopenia as assessed by the finger-circle test; while the explanatory variables were age, sex, BMl, alcohol consumption, smoking status, living status, socioeconomic status, self-reported health, self-reported physical fitness, exercise habits, mastication function, number of meals, sleep status, short-term cognitive ability, and gait speed. We chose this model because a previous study reported that most of the above variables are associated with the prevalence of sarcopenia [30]. The results of these analysis were reported as odds ratios (OR) and $95 \%$ confidence intervals (Cl). For each variable, the following reference groups were used to calculate the OR: age 40-49 years, male sex, BMI 18.5-24.9 kg/m², non-drinker, never-smoker, living together, high socioeconomic status, good self-reported health, good self-reported physical fitness, "yes" to exercise habits, good mastication function, $\geq 3$ meals, good sleep status, good short-term cognitive ability, and normal gait speed. We also conducted a similar analysis including all the participants. To conduct the sensitivity analysis for assessing the robustness of the above results, we conducted a similar analysis using the complete cases dataset [31].

In the statistical analyses, $p$-values $<0.05$ were considered significant. All analyses were performed using the JMP Pro, version 13.2 (SAS Institute, Inc., Cary, NC, USA) and/or R software 3.4.3 (R Development Core Team, Vienna, Austria).

\section{Ethical considerations}

Regarding the Settsu and Hannan mail surveys, we filed an application for an ethical review with the National Institutes of Biomedical Innovation, Health and Nutrition Institutional Review Board (Number: kenei 89, December 3, 2018). An ethical review was deemed unnecessary for the following reasons: 1) no one other than the supervisors at Settsu and Hannan had access to the residents' information; and 2) the mail surveys were anonymous and contained no information that could be used to identify the individuals. When we sent out the survey forms, we included a document that explained the following: the objective of the study, our methods for selecting the participants, that the returning of the survey form constituted consent to participate in the study, and that the survey forms were color-coded by school zone. The Settsu City face-to-face survey was approved by the Research Ethics Committee of the National Institutes of Biomedical Innovation, Health and Nutrition (Ikikenhatsu-178-1) and has been registered with the University Hospital Medical Information Network in Japan clinical

Page $4 / 16$ 
trial registration system (UMIN000036880). Study procedures as well as the risks associated with participating were explained and written informed consent was obtained from all the participants. Moreover, all the study procedures were performed in accordance with relevant guidelines/regulations.

\section{Results}

\section{Participant characteristics}

Table 1 shows the participants' characteristics for the mail and face-to-face surveys. In the mail survey, we did not observe any major differences in characteristics between Settsu and Hannan participants. The face-to-face survey participants, in whom we measured the body composition, were older and comprised a higher percentage of women than the mail survey participants. Participants with missing values were largely older adults but did not differ from those with complete cases in terms of sex (see Table S1 in Additional file 1).

Table 1 Participant characteristics in mail and face-to-face surveys

\begin{tabular}{|c|c|c|c|c|c|c|}
\hline \multirow[b]{3}{*}{ Age [years] ${ }^{\mathrm{b}}$} & \multicolumn{4}{|c|}{ Mail survey ${ }^{a}$} & \multirow{2}{*}{\multicolumn{2}{|c|}{$\begin{array}{l}\text { Face-to-face } \\
\text { Settsu City } \\
(n=525)\end{array}$}} \\
\hline & \multicolumn{2}{|c|}{$\begin{array}{l}\text { Settsu City } \\
(n=5300)\end{array}$} & \multicolumn{2}{|c|}{$\begin{array}{l}\text { Hannan City } \\
(n=4037)\end{array}$} & & \\
\hline & 62.8 & $(12.5)$ & 63.5 & $(12.2)$ & 70.6 & $(9.9)$ \\
\hline Women $[n(\%)]^{c}$ & 2496 & $(47.1)$ & 1965 & $(48.7)$ & 436 & $(83.0)$ \\
\hline $\mathrm{BMI}\left[\mathrm{kg} / \mathrm{m}^{2}\right]^{\mathrm{b}}$ & 23.2 & $(3.6)$ & 23.1 & $(3.8)$ & 22.5 & $(3.2)$ \\
\hline Alcohol drinker $[n(\%)]^{\mathrm{c}}$ & 3844 & $(72.5)$ & 2836 & $(70.3)$ & 312 & $(59.4)$ \\
\hline Current smoker $[n(\%)]^{\mathrm{c}}$ & 1045 & $(19.7)$ & 581 & $(14.4)$ & 18 & $(3.4)$ \\
\hline Living alone $[n(\%)]^{\mathrm{c}}$ & 694 & $(13.1)$ & 477 & $(11.8)$ & 131 & $(25.0)$ \\
\hline High socioeconomic status $[n(\%)]^{c}$ & 2819 & $(53.2)$ & 2386 & $(59.1)$ & 385 & $(73.8)$ \\
\hline Poor self-reported health $[n(\%)]^{c}$ & 1027 & $(19.4)$ & 595 & $(14.7)$ & 85 & $(16.2)$ \\
\hline Poor self-reported PF $[n(\%)]^{c}$ & 2553 & $(48.2)$ & 1707 & $(42.3)$ & 256 & $(48.8)$ \\
\hline Exercise habits per week $[n(\%)]^{\mathrm{c}}$ & 2813 & $(53.1)$ & 2265 & $(56.1)$ & 129 & $(24.6)$ \\
\hline Poor mastication $[n(\%)]^{\mathrm{c}}$ & 1035 & $(19.5)$ & 653 & $(16.2)$ & 79 & $(15.0)$ \\
\hline Number of meals $\geq 3$ times $[n(\%)]^{c}$ & 4548 & $(85.8)$ & 3588 & $(88.9)$ & 493 & (93.9) \\
\hline Poor sleep status $[n(\%)]^{c}$ & 1428 & $(26.9)$ & 912 & $(22.6)$ & 111 & $(21.1)$ \\
\hline Poor short cognitive ability $[n(\%)]^{c}$ & 446 & $(8.4)$ & 277 & $(6.9)$ & 57 & $(10.9)$ \\
\hline Slow gait speed $[n(\%)]^{c}$ & 1840 & $(34.7)$ & 1294 & $(32.1)$ & 238 & $(45.3)$ \\
\hline
\end{tabular}

BMI, body mass index; PF, physical fitness

${ }^{a}$ Data for participants with missing values in mail survey were imputed using multiple imputation $(n=[n$ in Settsu City] and [ $n$ in Hannan City]): $\operatorname{BMI}(n=208$ and 210), alcohol status ( $n=28$ and 8$)$, smoking status y ( $n=73$ and 6), family structure ( $n=141$ and 8$)$, socioeconomic status ( $n=126$ and 143), self-reported health ( $n=83$ and 107), self-reported physical fitness ( $n=82$ and 109), exercise habits $(n=91$ and 106), mastication ( $n=67$ and 114), number of meals ( $n=37$ and 173), sleep status ( $n=80$ and 109), cognitive status $(n=98$ and 106$)$, and gait speed $(n=93$ and 110$)$.

${ }^{\mathrm{b}}$ Continuous variables were shown in mean (standard deviation).

${ }^{\mathrm{c}}$ Category variables were shown in the number of people (\%). 
Table S2 in Additional file 1 shows the relationships of the finger-circle test results with the height and body composition. The finger-circle test demonstrated significant associations with body fat, ALM, SMI, and other body composition elements. Table 2 shows the validity of the finger-circle test for assessing sarcopenia. The prevalence of sarcopenia (by SMI in the face-to-face study) was 9.3\% (49/525). Finger-circle test response of "calf is smaller than finger-circle" was moderately predictive of the presence of sarcopenia as defined by SMI (AUROC: 0.666 [95\% Cl: 0.588 to 0.744$]$ ). The same relationship was observed when we stratified the those by age or sex. Therefore, we considered the participants whose finger-circle test response was "calf is smaller than finger-circle" as having sarcopenia.

Table 2 Area under the receiver operating characteristic curves for the finger-circle (yubi-wakka) test

\begin{tabular}{|c|c|c|c|c|c|c|c|c|c|c|c|c|c|c|}
\hline & \multicolumn{6}{|c|}{ Finger-circle test $^{a}$} & \multicolumn{8}{|c|}{ By finger-circle test (smaller) ${ }^{b}$} \\
\hline & \multicolumn{2}{|c|}{ Bigger } & \multicolumn{2}{|c|}{ Just fits } & \multicolumn{2}{|c|}{ Smaller } & \multirow[t]{2}{*}{ Sensitivity } & \multirow[t]{2}{*}{ Specificity } & \multirow[t]{2}{*}{ PPV } & \multirow[t]{2}{*}{ NPV } & \multirow[t]{2}{*}{ LR+ } & \multirow[t]{2}{*}{ LR- } & \multicolumn{2}{|c|}{$\begin{array}{l}\text { AUROC (95\% } \\
\mathrm{Cl})\end{array}$} \\
\hline $\begin{array}{l}\text { Total }(n= \\
525)\end{array}$ & & & & & & & & & & & & & & \\
\hline $\begin{array}{l}\text { Sarcopenia, } \\
n^{c}\end{array}$ & 11 & $(2.1)$ & 21 & $(4.0)$ & 17 & $(3.2)$ & \multirow[t]{2}{*}{34.7} & \multirow[t]{2}{*}{87.6} & \multirow[t]{2}{*}{22.4} & \multirow[t]{2}{*}{92.9} & \multirow[t]{2}{*}{2.8} & \multirow[t]{2}{*}{0.7} & \multirow[t]{2}{*}{0.666} & \multirow[t]{2}{*}{$\begin{array}{l}(0.588 \\
\text { to } \\
0.744)\end{array}$} \\
\hline $\begin{array}{l}\text { Non- } \\
\text { sarcopenia, } \\
n\end{array}$ & 223 & $(42.5)$ & 194 & $(37.0)$ & 59 & $(11.2)$ & & & & & & & & \\
\hline \multicolumn{15}{|l|}{$\begin{array}{l}\text { Women }(n= \\
\text { 436) }\end{array}$} \\
\hline $\begin{array}{l}\text { Sarcopenia, } \\
n^{c}\end{array}$ & 6 & $(1.4)$ & 14 & $(3.2)$ & 13 & $(3.0)$ & \multirow[t]{2}{*}{39.4} & \multirow[t]{2}{*}{87.1} & \multirow[t]{2}{*}{20.0} & \multirow[t]{2}{*}{94.6} & \multirow[t]{2}{*}{3.1} & \multirow[t]{2}{*}{0.7} & \multirow[t]{2}{*}{0.691} & \multirow[t]{2}{*}{$\begin{array}{l}(0.543 \\
\text { to } \\
0.839)\end{array}$} \\
\hline $\begin{array}{l}\text { Non- } \\
\text { sarcopenia, } \\
n\end{array}$ & 183 & $(41.9)$ & 168 & $(38.5)$ & 52 & $(12.0)$ & & & & & & & & \\
\hline \multicolumn{15}{|l|}{$\begin{array}{l}\text { Men }(n= \\
89)\end{array}$} \\
\hline $\begin{array}{l}\text { Sarcopenia, } \\
n^{c}\end{array}$ & 5 & $(5.6)$ & 7 & $(7.9)$ & 4 & $(4.5)$ & \multirow[t]{2}{*}{25.0} & \multirow[t]{2}{*}{90.4} & \multirow[t]{2}{*}{36.4} & 84.6 & 2.6 & 0.8 & 0.641 & $\begin{array}{l}(0.549 \\
\text { to } \\
0.733)\end{array}$ \\
\hline $\begin{array}{l}\text { Non- } \\
\text { sarcopenia, } \\
n\end{array}$ & 40 & $(44.9)$ & 26 & $(29.2)$ & 7 & $(7.9)$ & & & & & & & & \\
\hline $\begin{array}{l}<65 \text { years }(n \\
=107)\end{array}$ & & & & & & & & & & & & & & \\
\hline $\begin{array}{l}\text { Sarcopenia, } \\
n^{c}\end{array}$ & 1 & $(0.9)$ & 1 & $(0.9)$ & 2 & (1.9) & 50.0 & 94.2 & 25.0 & 98.0 & 8.6 & 0.5 & 0.729 & $\begin{array}{l}(0.459 \\
\text { to } \\
0.999)\end{array}$ \\
\hline $\begin{array}{l}\text { Non- } \\
\text { sarcopenia, } \\
n\end{array}$ & 52 & $(48.6)$ & 45 & $(42.1)$ & 6 & (5.6) & & & & & & & & \\
\hline $\begin{array}{l}\geq 65 \text { years } \\
(n=418)\end{array}$ & & & & & & & & & & & & & & \\
\hline $\begin{array}{l}\text { Sarcopenia, } \\
n^{c}\end{array}$ & 10 & $(2.4)$ & 20 & $(4.8)$ & 15 & (3.6) & 33.3 & 86.5 & 22.1 & 91.4 & 2.3 & 0.8 & 0.653 & $\begin{array}{l}(0.571 \\
\text { to } \\
0.735)\end{array}$ \\
\hline $\begin{array}{l}\text { Non- } \\
\text { sarcopenia, } \\
n\end{array}$ & 171 & $(40.9)$ & 149 & (35.6) & 53 & (12.7) & & & & & & & & \\
\hline
\end{tabular}

AUROC, area under the receiver operating characteristic curves; Cl, confidence interval; LR+, positive likelihood ratio.; LR-, negative likelihood ratio; NPV, negative predictive value; PPV, positive predictive value

${ }^{\text {a }}$ Compare the size of the finger-circle to the thickness (circumference) of the thickest part of your calf (calf is smaller [smaller], calf and finger-circle are about the same size [same size], or calf is bigger [bigger])." 
${ }^{b}$ Sarcopenia was defined by a skeletal muscle mass index (evaluated by the bioimpedance method) of $<7.0 \mathrm{~kg} / \mathrm{m}^{2}$ in $\mathrm{men}$ and $<5.7 \mathrm{~kg} / \mathrm{m}^{2}$ in women, in accordance with the AWGS 2019 Consensus.

c Those whose finger-circle test response was "smaller" were defined as having sarcopenia.

\section{Prevalence and factors associated with sarcopenia}

Table 3 shows the prevalence of sarcopenia according to the finger-circle test in the Settsu and Hannan mail surveys. The weighted prevalence of sarcopenia in Settsu and Hannan was $12.9 \%$ (95\% Cl: 12.0 to 13.8 ) and $12.8 \%$ (95\% Cl: 11.7 to 13.8$)$, respectively. While the prevalence of sarcopenia was higher in older adults (approximately 16\%) than in middle-aged adults, sarcopenia was nevertheless present in approximately 8-9\% of middle-aged participants (aged 40-59 years). Table 4 shows the comparisons of characteristics between participants with and without sarcopenia according to the finger-circle test. Factors that were associated with the prevalence of sarcopenia in both Settsu and Hannan were age, BMI, smoking status, and self-reported health. Table 5 shows the multivariate analysis factors associated with the prevalence of finger-circle test sarcopenia. As in the univariate analysis, ORs for the prevalence of sarcopenia were high with old age, low BMI, smoking, and poor self-reported health in participants from both Settsu and Hannan. In the analysis including all the participants, the prevalence of sarcopenia was additionally related to the number of meals. The same results were obtained during the complete cases sensitivity analysis (see Table S3 in Additional file 1).

Table 3 Prevalence of sarcopenia stratified by age and sex in Settsu and Hannan Cities

\begin{tabular}{|c|c|c|c|c|c|c|c|c|c|c|}
\hline & \multicolumn{5}{|c|}{ Settsu City } & \multicolumn{5}{|c|}{ Hannan City } \\
\hline & \multirow[t]{2}{*}{$n$} & \multicolumn{2}{|l|}{ Crude } & \multicolumn{2}{|c|}{ Weighted tabulation } & \multirow[t]{2}{*}{$n$} & \multicolumn{2}{|c|}{ Crude } & \multicolumn{2}{|c|}{ Weighted tabulation } \\
\hline \multicolumn{9}{|l|}{ Total } & & \\
\hline $40-49$ years & 1104 & 8.7 & (7.0 to 10.4 ) & 8.8 & (7.1 to 10.5 ) & 701 & 8.3 & (6.2 to 10.3 ) & 8.4 & (6.3 to 10.4 ) \\
\hline $50-59$ years & 965 & 8.5 & (6.7 to 10.3 ) & 8.5 & (6.8 to 10.3 ) & 785 & 9.3 & (7.3 to 11.3 ) & 9.4 & (7.4 to 11.4 ) \\
\hline $60-69$ years & 1343 & 12.3 & (10.5 to 14.0$)$ & 12.1 & (10.4 to 13.9 ) & 1088 & 10.1 & (8.3 to 11.9 ) & 10.4 & (8.6 to 12.2 ) \\
\hline $70-79$ years & 1488 & 17.6 & (15.7 to 19.5$)$ & 17.7 & (15.8 to 19.6 ) & 1144 & 16.4 & (14.3 to 18.6$)$ & 16.5 & (14.4 to 18.7 ) \\
\hline$\geq 80$ years & 400 & 21.8 & (17.7 to 25.8$)$ & 23.7 & (19.5 to 27.8 ) & 319 & 22.9 & (18.3 to 27.5 ) & 22.6 & (18.0 to 27.2 ) \\
\hline Overall & 5300 & 13.1 & (12.1 to 14.0$)$ & 12.9 & (12.0 to 13.8 ) & 4037 & 12.4 & (11.4 to 13.5 ) & 12.8 & (11.7 to 13.8 ) \\
\hline \multicolumn{11}{|l|}{ Men } \\
\hline $40-49$ years & 646 & 9.4 & (7.2 to 11.7 ) & 9.5 & (7.2 to 11.7 ) & 378 & 9.5 & (6.6 to 12.5$)$ & 9.9 & (6.9 to 12.9 ) \\
\hline $50-59$ years & 553 & 10.5 & (7.9 to 13.0 ) & 10.5 & (8.0 to 13.1 ) & 413 & 8.7 & (6.0 to 11.4 ) & 9.0 & (6.2 to 11.7 ) \\
\hline $60-69$ years & 713 & 13.2 & (10.7 to 15.7 ) & 13.1 & (10.6 to 15.5 ) & 578 & 10.7 & (8.2 to 13.2 ) & 10.7 & (8.2 to 13.2 ) \\
\hline $70-79$ years & 717 & 16.3 & (13.6 to 19.0$)$ & 16.6 & (13.9 to 19.3 ) & 559 & 16.5 & (13.4 to 19.5$)$ & 16.4 & (13.3 to 19.4 ) \\
\hline$\geq 80$ years & 175 & 26.3 & (19.8 to 32.8 ) & 30.5 & (23.7 to 37.3 ) & 144 & 23.6 & (16.7 to 30.5 ) & 21.4 & (14.7 to 28.1 ) \\
\hline Overall & 2804 & 13.4 & (12.1 to 14.7 ) & 13.6 & (12.3 to 14.9 ) & 2072 & 12.5 & (11.1 to 14.0 ) & 12.6 & (11.2 to 14.1 ) \\
\hline \multicolumn{11}{|l|}{ Women } \\
\hline 40-49 years & 458 & 7.6 & (5.2 to 10.1 ) & 7.8 & (5.4 to 10.3 ) & 323 & 6.8 & (4.1 to 9.6 ) & 7.2 & (4.4 to 10.0 ) \\
\hline $50-59$ years & 412 & 5.8 & (3.6 to 8.1 ) & 6.0 & (3.7 to 8.3 ) & 372 & 9.9 & (6.9 to 13.0 ) & 10.1 & (7.0 to 13.2 ) \\
\hline $60-69$ years & 630 & 11.3 & (8.8 to 13.7 ) & 11.0 & (8.6 to 13.5 ) & 510 & 9.4 & (6.9 to 11.9 ) & 9.7 & (7.1 to 12.3 ) \\
\hline $70-79$ years & 771 & 18.8 & (16.0 to 21.6 ) & 19.1 & (16.4 to 21.9 ) & 585 & 16.4 & (13.4 to 19.4 ) & 16.5 & (13.5 to 19.5 ) \\
\hline$\geq 80$ years & 225 & 18.2 & (13.2 to 23.3 ) & 21.4 & (16.1 to 26.8 ) & 175 & 22.3 & (16.1 to 28.5 ) & 21.6 & (15.5 to 27.7 ) \\
\hline Overall & 2496 & 12.7 & (11.4 to 14.0$)$ & 12.4 & (11.1 to 13.7 ) & 1965 & 12.3 & (10.9 to 13.8 ) & 12.6 & (11.2 to 14.1 ) \\
\hline
\end{tabular}

The values represent the prevalence of sarcopenia ( $95 \%$ confidence intervals). Weighted tabulation was calculated by adjusting the composition ratio of the samples collected from the mail survey to the composition ratio of the population provided by the municipalities of Settsu and Hannan Cities. 
Table 4 Comparison of participant characteristics between sarcopenia and non-sarcopenia groups

\begin{tabular}{|c|c|c|c|c|c|c|c|c|c|c|}
\hline & \multicolumn{4}{|c|}{ Settsu City } & \multirow[t]{3}{*}{$p$-value } & \multicolumn{4}{|c|}{ Hannan City } & \multirow[t]{3}{*}{$p$-value } \\
\hline & \multicolumn{2}{|c|}{$\begin{array}{l}\text { Non-sarcopenia } \\
(n=4608)\end{array}$} & \multicolumn{2}{|c|}{$\begin{array}{l}\text { Sarcopenia } \\
(n=692)\end{array}$} & & \multicolumn{2}{|c|}{$\begin{array}{l}\text { Non-sarcopenia } \\
(n=3535)\end{array}$} & \multicolumn{2}{|c|}{$\begin{array}{l}\text { Sarcopenia } \\
(n=502)\end{array}$} & \\
\hline & $n$ & $(\%)$ & $n$ & $(\%)$ & & $n$ & $(\%)$ & $n$ & $(\%)$ & \\
\hline \multicolumn{11}{|l|}{ Age [years] } \\
\hline $40-49$ & 1008 & $(91.3)$ & 96 & (8.7) & $<0.001$ & 643 & $(91.7)$ & 58 & $(8.3)$ & $<0.001$ \\
\hline $50-59$ & 883 & $(91.5)$ & 82 & $(8.5)$ & & 712 & $(90.7)$ & 73 & $(9.3)$ & \\
\hline $60-69$ & 1178 & $(87.7)$ & 165 & $(12.3)$ & & 978 & $(89.9)$ & 110 & $(10.1)$ & \\
\hline $70-79$ & 1226 & $(82.4)$ & 262 & $(17.6)$ & & 956 & $(83.6)$ & 188 & $(16.4)$ & \\
\hline$\geq 80$ & 313 & $(78.3)$ & 87 & $(21.8)$ & & 246 & $(77.1)$ & 73 & $(22.9)$ & \\
\hline Women & 2180 & $(47.3)$ & 316 & $(45.7)$ & 0.419 & 1723 & $(48.7)$ & 242 & $(48.2)$ & 0.823 \\
\hline \multicolumn{11}{|l|}{ BMI $\left[\mathrm{kg} / \mathrm{m}^{2}\right]$} \\
\hline$<18.5$ & 196 & $(57.0)$ & 148 & $(43.0)$ & $<0.001$ & 122 & $(51.3)$ & 116 & $(48.7)$ & $<0.001$ \\
\hline $18.5-24.9$ & 3031 & $(86.3)$ & 481 & $(13.7)$ & & 2482 & $(88.0)$ & 340 & $(12.0)$ & \\
\hline $25.0-29.9$ & 1149 & $(95.3)$ & 57 & $(4.7)$ & & 776 & $(95.1)$ & 40 & $(4.9)$ & \\
\hline$\geq 30$ & 232 & $(97.5)$ & 6 & $(2.5)$ & & 155 & $(96.3)$ & 6 & (3.7) & \\
\hline Alcohol drinker & 3371 & $(73.2)$ & 473 & $(68.4)$ & 0.009 & 2498 & $(70.7)$ & 338 & $(67.3)$ & 0.129 \\
\hline \multicolumn{11}{|l|}{ Smoking status } \\
\hline Never & 2295 & $(87.4)$ & 330 & $(12.6)$ & 0.036 & 1973 & $(88.6)$ & 255 & $(11.4)$ & 0.049 \\
\hline Past & 1426 & $(87.5)$ & 204 & $(12.5)$ & & 1056 & $(86.0)$ & 172 & $(14.0)$ & \\
\hline Current & 887 & $(84.9)$ & 158 & $(15.1)$ & & 506 & $(87.1)$ & 75 & $(12.9)$ & \\
\hline Living alone & 601 & $(13.0)$ & 93 & $(13.4)$ & 0.774 & 409 & $(11.6)$ & 68 & $(13.5)$ & 0.207 \\
\hline High socioeconomic status & 2465 & $(53.5)$ & 354 & $(51.2)$ & 0.251 & 2089 & $(59.1)$ & 297 & $(59.2)$ & 0.977 \\
\hline Poor self-reported health & 862 & $(18.7)$ & 165 & $(23.8)$ & 0.002 & 493 & $(13.9)$ & 102 & $(20.3)$ & $<0.001$ \\
\hline Poor self-reported PF & 2197 & $(47.7)$ & 356 & $(51.4)$ & 0.065 & 1489 & $(42.1)$ & 218 & $(43.4)$ & 0.580 \\
\hline Exercise habits per & 2446 & $(53.1)$ & 367 & $(53.0)$ & 0.982 & 1978 & $(56.0)$ & 287 & $(57.2)$ & 0.607 \\
\hline Poor mastication & 850 & $(18.4)$ & 185 & $(26.7)$ & $<0.001$ & 556 & $(15.7)$ & 97 & $(19.3)$ & 0.045 \\
\hline \multicolumn{11}{|l|}{ Number of meals [times] } \\
\hline 1 & 50 & $(83.3)$ & 10 & $(16.7)$ & 0.339 & 21 & $(80.8)$ & 5 & $(19.2)$ & 0.083 \\
\hline 2 & 602 & $(87.0)$ & 90 & $(13.0)$ & & 364 & $(86.1)$ & 59 & $(13.9)$ & \\
\hline$\geq 3$ & 3956 & $(87.0)$ & 592 & $(13.0)$ & & 3150 & $(87.8)$ & 438 & $(12.2)$ & \\
\hline Poor sleep status & 1239 & $(26.9)$ & 189 & $(27.3)$ & 0.815 & 802 & $(22.7)$ & 110 & $(21.9)$ & 0.697 \\
\hline Poor short cognitive ability & 378 & $(8.2)$ & 68 & $(9.8)$ & 0.160 & 235 & $(6.6)$ & 42 & $(8.4)$ & 0.165 \\
\hline Slow gait speed & 1547 & $(33.6)$ & 293 & $(42.3)$ & $<0.001$ & 1126 & $(31.9)$ & 168 & $(33.5)$ & 0.470 \\
\hline
\end{tabular}

BMI, body mass index; PF, physical fitness

The values are shown as number of cases (\%) and were analyzed using the Chi-square test.

Table 5 Odds ratios for the prevalence and factors associated with sarcopenia using multivariate logistic regression analyses 


\begin{tabular}{|c|c|c|c|c|c|c|c|c|c|c|}
\hline \multirow{3}{*}{$\begin{array}{l}\text { Variables [Reference] } \\
\text { Age [ } 40-49 \text { years] }\end{array}$} & \multirow{3}{*}{$\begin{array}{l}\text { Categories } \\
50-59\end{array}$} & \multicolumn{3}{|c|}{ Total $^{a}$} & \multicolumn{3}{|c|}{ Settsu City } & \multicolumn{3}{|c|}{ Hannan City } \\
\hline & & \multicolumn{2}{|c|}{ ORs $(95 \% \mathrm{Cl})$} & \multirow{2}{*}{$\begin{array}{l}p- \\
\text { value } \\
0.736\end{array}$} & \multicolumn{2}{|c|}{ ORs $(95 \% \mathrm{Cl})$} & \multirow{2}{*}{$\begin{array}{l}p- \\
\text { value } \\
0.681\end{array}$} & \multicolumn{2}{|c|}{ ORs $(95 \% \mathrm{Cl})$} & \multirow{2}{*}{$\begin{array}{l}p- \\
\text { value } \\
0.328\end{array}$} \\
\hline & & 1.04 & $\begin{array}{l}(0.82 \text { to } \\
1.33)\end{array}$ & & 0.94 & $\begin{array}{l}(0.68 \text { to } \\
1.29)\end{array}$ & & 1.21 & $\begin{array}{l}(0.83 \text { to } \\
1.77)\end{array}$ & \\
\hline & $60-69$ & 1.41 & $\begin{array}{l}(1.13 \text { to } \\
1.75)\end{array}$ & 0.003 & 1.43 & $\begin{array}{l}(1.07 \text { to } \\
1.90)\end{array}$ & 0.014 & 1.37 & $\begin{array}{l}(0.96 \text { to } \\
1.96)\end{array}$ & 0.081 \\
\hline & $70-79$ & 2.33 & $\begin{array}{l}(1.87 \text { to } \\
2.90)\end{array}$ & $<0.001$ & 2.22 & $\begin{array}{l}(1.68 \text { to } \\
2.94)\end{array}$ & $<0.001$ & 2.47 & $\begin{array}{l}(1.73 \text { to } \\
3.50)\end{array}$ & $<0.001$ \\
\hline & $\geq 80$ & 3.23 & $\begin{array}{l}(2.44 \text { to } \\
4.26)\end{array}$ & $<0.001$ & 2.85 & $\begin{array}{l}(1.98 \text { to } \\
4.11)\end{array}$ & $<0.001$ & 3.90 & $\begin{array}{l}(2.53 \text { to } \\
6.02)\end{array}$ & $<0.001$ \\
\hline Sex [Men] & Women & 0.96 & $\begin{array}{l}(0.82 \text { to } \\
1.13)\end{array}$ & 0.626 & 0.97 & $\begin{array}{l}(0.79 \text { to } \\
1.19)\end{array}$ & 0.783 & 0.93 & $\begin{array}{l}(0.72 \text { to } \\
1.20)\end{array}$ & 0.557 \\
\hline \multirow[t]{3}{*}{ BMI [18.5-24.9 kg/m²] } & $<18.5$ & 5.80 & $\begin{array}{l}(4.81 \text { to } \\
7.00)\end{array}$ & $<0.001$ & 4.96 & $\begin{array}{l}(3.88 \text { to } \\
6.34)\end{array}$ & $<0.001$ & 7.26 & $\begin{array}{l}(5.42 \text { to } \\
9.72)\end{array}$ & $<0.001$ \\
\hline & $25.0-29.9$ & 0.33 & $\begin{array}{l}(0.26 \text { to } \\
0.41)\end{array}$ & $<0.001$ & 0.30 & $\begin{array}{l}(0.22 \text { to } \\
0.40)\end{array}$ & $<0.001$ & 0.38 & $\begin{array}{l}(0.27 \text { to } \\
0.53)\end{array}$ & $<0.001$ \\
\hline & $\geq 30$ & 0.22 & $\begin{array}{l}(0.12 \text { to } \\
0.39)\end{array}$ & $<0.001$ & 0.17 & $\begin{array}{l}(0.07 \text { to } \\
0.39)\end{array}$ & $<0.001$ & 0.29 & $\begin{array}{l}(0.13 \text { to } \\
0.68)\end{array}$ & 0.004 \\
\hline $\begin{array}{l}\text { Alcohol status [Non- } \\
\text { drinker] }\end{array}$ & Drinker & 0.90 & $\begin{array}{l}(0.77 \text { to } \\
1.04)\end{array}$ & 0.150 & 0.88 & $\begin{array}{l}(0.73 \text { to } \\
1.07)\end{array}$ & 0.212 & 0.91 & $\begin{array}{l}(0.72 \text { to } \\
1.14)\end{array}$ & 0.396 \\
\hline \multirow[t]{2}{*}{$\begin{array}{l}\text { Smoking status [Never- } \\
\text { smoker] }\end{array}$} & Past & 1.21 & $\begin{array}{l}(1.02 \text { to } \\
1.43)\end{array}$ & 0.033 & 1.07 & $\begin{array}{l}(0.85 \text { to } \\
1.34)\end{array}$ & 0.578 & 1.42 & $\begin{array}{l}(1.08 \text { to } \\
1.85)\end{array}$ & 0.011 \\
\hline & Current & 1.44 & $\begin{array}{l}(1.18 \text { to } \\
1.76)\end{array}$ & $<0.001$ & 1.45 & $\begin{array}{l}(1.13 \text { to } \\
1.86)\end{array}$ & 0.004 & 1.38 & $\begin{array}{l}(1.02 \text { to } \\
1.93)\end{array}$ & 0.044 \\
\hline $\begin{array}{l}\text { Living status [Living } \\
\text { together] }\end{array}$ & Alone & 0.92 & $\begin{array}{l}(0.76 \text { to } \\
1.11)\end{array}$ & 0.372 & 0.87 & $\begin{array}{l}(0.68 \text { to } \\
1.12)\end{array}$ & 0.297 & 1.01 & $\begin{array}{l}(0.75 \text { to } \\
1.36)\end{array}$ & 0.973 \\
\hline $\begin{array}{l}\text { Socioeconomic status } \\
\text { [High] }\end{array}$ & Low & 1.05 & $\begin{array}{l}(0.92 \text { to } \\
1.20)\end{array}$ & 0.472 & 1.06 & $\begin{array}{l}(0.89 \text { to } \\
1.27)\end{array}$ & 0.491 & 1.06 & $\begin{array}{l}(0.85 \text { to } \\
1.31)\end{array}$ & 0.620 \\
\hline Self-reported health [Good] & Poor & 1.45 & $\begin{array}{l}(1.20 \text { to } \\
1.75)\end{array}$ & $<0.001$ & 1.28 & $\begin{array}{l}(1.01 \text { to } \\
1.62)\end{array}$ & 0.046 & 1.77 & $\begin{array}{l}(1.31 \text { to } \\
2.40)\end{array}$ & $<0.001$ \\
\hline Self-reported PF [Good] & Poor & 0.90 & $\begin{array}{l}(0.77 \text { to } \\
1.05)\end{array}$ & 0.186 & 0.93 & $\begin{array}{l}(0.76 \text { to } \\
1.14)\end{array}$ & 0.473 & 0.86 & $\begin{array}{l}(0.67 \text { to } \\
1.10)\end{array}$ & 0.229 \\
\hline $\begin{array}{l}\text { Exercise habits per week } \\
\text { [Yes] }\end{array}$ & No & 1.03 & $\begin{array}{l}(0.90 \text { to } \\
1.18)\end{array}$ & 0.674 & 1.05 & $\begin{array}{l}(0.88 \text { to } \\
1.26)\end{array}$ & 0.573 & 0.99 & $\begin{array}{l}(0.79 \text { to } \\
1.23)\end{array}$ & 0.898 \\
\hline $\begin{array}{l}\text { Mastication function } \\
\text { [Good] }\end{array}$ & Poor & 1.06 & $\begin{array}{l}(0.90 \text { to } \\
1.25)\end{array}$ & 0.490 & 1.17 & $\begin{array}{l}(0.95 \text { to } \\
1.44)\end{array}$ & 0.132 & 0.90 & $\begin{array}{l}(0.68 \text { to } \\
1.18)\end{array}$ & 0.438 \\
\hline \multirow[t]{2}{*}{$\begin{array}{l}\text { Number of meals }[\geq 3 \\
\text { times] }\end{array}$} & 2 & 1.14 & $\begin{array}{l}(0.93 \text { to } \\
1.39)\end{array}$ & 0.217 & 1.07 & $\begin{array}{l}(0.82 \text { to } \\
1.39)\end{array}$ & 0.619 & 1.27 & $\begin{array}{l}(0.92 \text { to } \\
1.75)\end{array}$ & 0.144 \\
\hline & 1 & 1.82 & $\begin{array}{l}(1.00 \text { to } \\
3.32)\end{array}$ & 0.049 & 1.80 & $\begin{array}{l}(0.88 \text { to } \\
3.68)\end{array}$ & 0.110 & 1.83 & $\begin{array}{l}(0.61 \text { to } \\
5.52)\end{array}$ & 0.280 \\
\hline Sleep status [Good] & Poor & 1.07 & $\begin{array}{l}(0.91 \text { to } \\
1.26)\end{array}$ & 0.401 & 1.11 & $\begin{array}{l}(0.91 \text { to } \\
1.36)\end{array}$ & 0.312 & 1.00 & $\begin{array}{l}(0.77 \text { to } \\
1.30)\end{array}$ & 0.987 \\
\hline $\begin{array}{l}\text { Short cognitive ability } \\
\text { [Good] }\end{array}$ & Poor & 1.18 & $\begin{array}{l}(0.94 \text { to } \\
1.48)\end{array}$ & 0.147 & 1.17 & $\begin{array}{l}(0.87 \text { to } \\
1.56)\end{array}$ & 0.296 & 1.23 & $\begin{array}{l}(0.85 \text { to } \\
1.77)\end{array}$ & 0.277 \\
\hline Gait speed [Normal] & Slow & 1.06 & $\begin{array}{l}(0.91 \text { to } \\
1.23)\end{array}$ & 0.481 & 1.20 & $\begin{array}{l}(0.98 \text { to } \\
1.47)\end{array}$ & 0.072 & 0.88 & $\begin{array}{l}(0.69 \text { to } \\
1.12)\end{array}$ & 0.299 \\
\hline
\end{tabular}

$\mathrm{BMI}$, body mass index; $\mathrm{Cl}$, confidence interval; OR, odds ratio; $\mathrm{PF}$, physical fitness

The values were shown in odds ratios ( $95 \%$ confidence intervals). 
a Multivariate adjusted model for the total number of participants was adjusted by adding the area (Settsu or Hannan Cities) to the covariates.

\section{Discussion}

In the present study, we determined the prevalence of sarcopenia screened by finger-circle test among community-dwelling middle-aged and older adults (age $\geq 40$ years) residing in Settsu and Hannan Cities, Osaka Prefecture, Japan and conducted an exploratory analysis of factors associated with sarcopenia based on the survey items. Based on sarcopenia (defined by bioimpedance-measured SMI), we confirmed the finger-circle test as a valid method of sarcopenia assessment. In all participants, age, BMI, smoking status, self-reported health, and number of meals were associated with the prevalence of sarcopenia. To the best of our knowledge, the present study is the first to determine the prevalence and factors associated with sarcopenia screened by finger-circle test in middle-aged and older Japanese adults. Our study's findings may be useful for a population-based health approach targeting sarcopenia for prevention.

We evaluated the validity of the finger-circle test for assessing sarcopenia (defined by SMI). The finger-circle test for predicting sarcopenia (by SMI) was found to be less sensitive but more specific than reported in a previous study using calf circumference as a screening tool for sarcopenia [12]. This result implies that the finger-circle test may be likely to identify sarcopenia in individuals who do not actually have it and be able to accurately indicate when sarcopenia is not present in individuals. It is important for screening tools to be able to cheaply and rapidly distinguish between high and low risk individuals for diseases and disorders, prior to definitive diagnostic tests in evidently healthy populations [32]. Our results indicated that the finger-circle test is sufficiently capable of screening out subjects who are less likely to have sarcopenia prior to the definitive diagnosis and is therefore potentially useful as a screening test. A study of middle-aged and older adult Japanese found calf circumferences of $34 \mathrm{~cm}$ for men and $33 \mathrm{~cm}$ for women to be the optimal cutoff points for predicting low muscle mass (defined by SMI) [11]. Similar results were also obtained in other studies [12, 13], and the AWGS 2019 Consensus also uses these cutoff values [2]. A study of community-dwelling Japanese adults aged $\geq 65$ years reported that the finger-circle circumference is roughly 33 and 31 $\mathrm{cm}$ for older adults men and women, respectively [14]. These findings showed that the cutoff values for the finger-circle and calf circumferences are relatively consistent for identifying individuals with low muscle mass (by SMI) and that the finger-circle test is a useful sarcopenia screening tool. However, the difference between the calf circumference cutoff for low muscle mass and finger-circle circumference is larger in women than in men (approximately 1 and $2 \mathrm{~cm}$ in men and women, respectively); these differences may affect the accuracy of the finger-circle test. In addition, the calf circumference as a screening tool for low muscle mass (defined by bioimpedanceassessed SMI) is less sensitive in women than in men (81.5\% vs. 91.2) [12]. Conceivable reasons for this difference in sensitivity include the larger fat volumes in the women's legs than in men's legs, and edema of the lower extremities [11]. Our data also showed the tendency of lower positive predictive value in women than in men. In addition, a previous study has reported that individuals whose finger-circle test response was "smaller" had larger finger-circle circumferences than individuals with other responses [14]. These errors in finger-circle test accuracy can perhaps be partially explained by the finger-circle circumference and sex. Therefore, the use of the finger-circle test to screen for sarcopenia requires a thorough understanding of the effects of sex and finger-circle circumference on systematic error.

We found the weighted prevalence of sarcopenia screened by the finger-circle test to be $12.9 \%$ in Settsu and $12.8 \%$ in Hannan. In both cities, sarcopenia was more prevalent among the older individuals (about 16\%) than among middle-aged individuals (about $9 \%$ ). A meta-analysis of 109 studies of older individuals reported that the prevalence of sarcopenia, defined by the European Working Group on Sarcopenia/AWGS criteria was $12.9 \%$ and that sarcopenia is more prevalent in oldest adults than in younger older adults [33]. In a study of community-dwelling adults in Singapore, the prevalence of sarcopenia (by the AWGS 2019 Consensus criteria) was approximately $2 \%$ and $7 \%$ in adults aged 40-49 and 50-59 years, respectively [21]. Using data from Korea National Health and Nutrition Examination Surveys, Moon et al reported the prevalence of sarcopenia (by SMI) in adults aged 40-59 years as 3.6\% [34]. From these studies, we speculated that the prevalence of sarcopenia assessed by the finger-circle test may be slightly higher in both middle-aged and older adults than the prevalence of sarcopenia defined by the gait speed, grip strength, or skeletal muscle mass. The finger-circle test is not a tool for definitively diagnosing sarcopenia but rather a screening tool that identifies individuals who are likely to have sarcopenia, which may explain why the finger-circle test yielded a higher prevalence of sarcopenia than that of the definitive diagnoses. Furthermore, skeletal muscle mass and grip strength tend to decline once individuals reach their thirties [25]; this may explain why sarcopenia also occurs in middle-aged adults. The above findings suggest that sarcopenia is not confined to the older adults and that its assessment must begin during middle age, when muscle strength and muscle mass begin to decline.

Our study showed that age, BMI, smoking status, self-reported health, and number of meals were associated with the prevalence of sarcopenia (by finger-circle test). A cross-sectional study of community-dwelling adults aged 28-95 years found that the age of 30 years marks the start of decline not only of grip strength but also of muscle quality [35]. The lower the number of meals taken (for example, skipping breakfast), the lower the total energy intake per day [36], and this may be associated with lower BMI [37]. In addition, a metaanalysis which examined the relation between smoking and prevalence of sarcopenia found a higher prevalence among smokers than

Page 10/16 
among non-smokers [22]. These intrinsic (age) and extrinsic (BMI, smoking status, and diet) factors have been identified as risk factors for sarcopenia [38], and these studies appear to support the results of our study. To the best of our knowledge, no previous studies have demonstrated that self-reported health is significantly associated with the prevalence of sarcopenia [20, 21]. However, previous studies reported that among older adults, sarcopenia defined by BMl-adjusted values of skeletal muscle mass [39] and grip strength [40] is more strongly associated with the risk of disability and the risk of composite outcomes such as falls and hospitalization than sarcopenia defined by methods that do not adjust for BMI. Therefore, the AWGS 2019 Consensus states that adjusting for measured muscle mass using BMI is the best method for defining sarcopenia [2]. In our study, we showed that self-reported health was significantly associated with the prevalence of sarcopenia even after adjusting for age and BMI. One study showed that individuals with sarcopenia have a low health-related quality of life [41]. Moreover, other studies demonstrated that several self-reported diseases are similarly associated with the prevalence of sarcopenia $[16,19,23]$. However, regarding the association between self-reported health and the prevalence of sarcopenia, it is unknown whether the development of sarcopenia from the above associations causes self-reported health to decline or whether the decline of selfreported health results in sarcopenia. Although the causal relationship between self-reported health and the prevalence of sarcopenia could be in the opposite direction, these results seem to provide an important finding: the possibility that poor self-reported health in communitydwelling adults needs to be resolved due to being related factors for prevalence of sarcopenia. Appropriately designed epidemiological studies are important for assessing novel risk factors that could affect healthy lifespans [42]. The prevalence and factors associated with sarcopenia in middle-aged and older adults that we demonstrated in the present study may be useful in designing policies that seek to promote health by lowering the prevalence of sarcopenia.

The strength of the present study is that it examined the prevalence of sarcopenia in two different cities in Osaka Prefecture and explored the factors associated with sarcopenia in residents aged $\geq 40$ years. The results for both cities were comparable. We also confirmed that the finger-circle test is a valid assessment of sarcopenia in comparison to sarcopenia assessed with the actual measurement of SMI. However, the methodology of this study was limited in several ways. First, our study was cross-sectional in design. Therefore, we could not infer whether the relationship observed between prevalence of sarcopenia and its associated factors was temporal or causal. Second, finger-circle test was only moderately (not particularly strongly) predictive of the presence of sarcopenia as defined by SMI (AUROC: 0.666). In addition, to verify the validity of the finger-circle test, we assessed sarcopenia via the actual measurements, but the measurements only reflected the muscle mass. The diagnostic criteria for sarcopenia include gait speed [43] and grip strength [44], which are associated with the risk of mortality among older adults. Therefore, the validity of the finger-circle test should be examined again compared with sarcopenia assessment based on muscle mass as well as grip strength and gait speed [1-4]. Third, the present study was a self-administered survey and may thus have included systematic error due to self-reporting. Also, although we conducted an exploratory examination of many potential factors associated with sarcopenia, we could not completely consider bias associated with factors we did not measure, such as educational history $[19,45]$ and the presence of disease $[19,23]$. Lastly, although we selected participants via stratified sampling by elementary school zone, the response rate for the mail survey was only $58.1 \%$ in Settsu and $60.0 \%$ in Hannan. Thus, the participants may have been more health-conscious than the general population, meaning that selection bias may have been present. In addition, the face-to-face survey participants, among whom validity of the finger-circle test was examined, were older and included a higher percentage of women than the mail survey participants. Thus, a limitation is the ability to extrapolate the validity of the finger-circle test obtained in the face-to-face survey to the participants in the mail survey. These limitations could prevent our results from being generalized. Therefore, it is necessary to conduct a prospective observational study, a randomized controlled trial, or another type of study with a better design than ours to assess whether the factors found in the present study are in fact associated with the risk of developing sarcopenia.

Our study showed that sarcopenia may be present not only among older adults but also among middle-aged adults (ages 40-59 years). A recent paradigm shift has seen a move away from a focus on individual diseases to an awareness that several chronic diseases have shared risk factors and that multiple coexisting disease states are strongly affected by the complexity of the health trajectories, disorders, and necessary care [46]. In Japan, specific health checkups and specific health guidance have been conducted since April 2008 to assess the risk of metabolic syndrome in middle-aged and older adults aged 40-74 years [47]. To extract cases of "possible sarcopenia", the AWGS 2019 Consensus recommends assessing the calf circumference in primary health care or community preventive services settings [2]. The fingercircle test, which does not require specialized techniques or instruments, can be performed by anyone and is a simpler sarcopenia screening tool than the assessment of the calf circumference. This aspect of the finger-circle test suggests that it should be added as a sarcopenia screening tool to the specific health checkups and specific health guidance currently conducted for middle-aged and older adults in Japan. This effort may enable the simultaneous evaluation of the risks of sarcopenia and metabolic syndrome from middle-age onward. Our study also suggested that providing individuals with an opportunity to identify their own health issue is crucial to lower the prevalence of sarcopenia.

\section{Conclusions}


Our study showed that the finger-circle test is a useful sarcopenia screening tool. In addition, we found that sarcopenia is present not only among older adults but also among middle-aged adults. Age, BMI, smoking status, self-reported health, and number of meals were all associated with the prevalence of sarcopenia. Our findings suggest that it is important to provide individuals with opportunities to be able to perform a test that could lead to the identification of sarcopenia, regardless of their age. The results of the present study may provide useful indications for developing public health programs that seek to prevent sarcopenia.

\section{Abbreviations}

AWGS: Asian Working Group for Sarcopenia; ALM: appendicular skeletal muscle mass; AUROC: area under the receiver operating characteristic curves; BMI: body mass index; Cl: confidence interval; MICE: multivariate imputation by chained equation; OR: odds ratio; SMI: skeletal muscle mass index

\section{Declarations}

\section{Ethics approval and consent to participate}

The need for ethical approval of mail survey was waived by the Research Ethics Committee of the National Institutes of Biomedical Innovation, Health and Nutrition. Ethical approval of the face-to-face survey was obtained from the Research Ethics Committee of the National Institutes of Biomedical Innovation, Health and Nutrition (Ikikenhatsu-178-1) and participants gave written informed consent at the beginning of the survey.

\section{Consent for publication}

Not applicable.

\section{Availability of data and materials}

Researchers can apply to our study group for permission to use this data through the T.Y. (t-yoshida@nibiohn.go.jp) or M.M. (miyachi@nibiohn.go.jp) on reasonable request.

\section{Competing interests}

The authors declare that they have no competing interests.

\section{Funding}

This study was carried out by a contract project cost from Division of the Health Promotion, Department of Health and Medical, Osaka Prefecture.

\section{Authors' contributions}

Study concept and design: D.W., T.Y., Y.Y., K.K., H.S., H.T., N.N., K.A., and M.M.; Acquisition of data: D.W., T.Y., T.N., N.S., K.T., H.S., N.N., and M.M.; Analysis and interpretation of data: D.W., T.Y., and M.M.; Drafting of the manuscript: D.W., and T.Y.; Critical revision of the manuscript for important intellectual content: D.W., T.Y., T.N., N.S., Y.Y., K.K., K.T., M.O., H.S., H.T., N.N., K.A., and M.M. All authors read and approved the final manuscript.

\section{Acknowledgements}

This study was conducted jointly by Settsu City and Hannan City, Osaka Prefecture, and the National Institute of Health and Nutrition, as part of the "Health Disparity Resolution Program Promotion Project (Frailty) in Osaka Prefecture." We acknowledge several administrators of Settsu and Hannan Cities and Osaka Prefecture. We wish to express our gratitude to all of the participants for their cooperation in this study. We would like to thank Editage (www.editage.jp) for English-language editing.

\section{References}

1. Cruz-Jentoft AJ, Bahat G, Bauer J, Boirie Y, Bruyere O, Cederholm T, Cooper C, Landi F, Rolland Y, Sayer AA et al: Sarcopenia: revised European consensus on definition and diagnosis. Age Ageing 2019, 48(1):16-31. 
2. Chen LK, Woo J, Assantachai P, Auyeung TW, Chou MY, lijima K, Jang HC, Kang L, Kim M, Kim S et al: Asian Working Group for Sarcopenia: 2019 Consensus Update on Sarcopenia Diagnosis and Treatment. J Am Med Dir Assoc 2020, 21(3):300-307 e302.

3. Fielding RA, Vellas B, Evans WJ, Bhasin S, Morley JE, Newman AB, Abellan van Kan G, Andrieu S, Bauer J, Breuille D et al: Sarcopenia: an undiagnosed condition in older adults. Current consensus definition: prevalence, etiology, and consequences. International working group on sarcopenia. J Am Med Dir Assoc 2011, 12(4):249-256.

4. Morley JE, Abbatecola AM, Argiles JM, Baracos V, Bauer J, Bhasin S, Cederholm T, Coats AJ, Cummings SR, Evans WJ et al: Sarcopenia with limited mobility: an international consensus. J Am Med Dir Assoc 2011, 12(6):403-409.

5. Brown JC, Harhay MO, Harhay MN: Sarcopenia and mortality among a population-based sample of community-dwelling older adults. $J$ Cachexia Sarcopenia Muscle 2016, 7(3):290-298.

6. Nakamura K, Yoshida D, Honda T, Hata J, Shibata M, Hirakawa Y, Furuta Y, Kishimoto H, Ohara T, Kitazono T et al: Prevalence and mortality of sarcopenia in a community-dwelling older Japanese population: the Hisayama Study. J Epidemio/ 2020.

7. Bianchi L, Ferrucci L, Cherubini A, Maggio M, Bandinelli S, Savino E, Brombo G, Zuliani G, Guralnik JM, Landi F et al: The Predictive Value of the EWGSOP Definition of Sarcopenia: Results From the InCHIANTI Study. J Gerontol A Biol Sci Med Sci 2016, 71(2):259-264.

8. Anker SD, Morley JE, von Haehling S: Welcome to the ICD-10 code for sarcopenia. J Cachexia Sarcopenia Muscle 2016, 7(5):512-514.

9. Caan BJ, Cespedes Feliciano EM, Prado CM, Alexeeff S, Kroenke CH, Bradshaw P, Quesenberry CP, Weltzien EK, Castillo AL, Olobatuyi TA et al: Association of Muscle and Adiposity Measured by Computed Tomography With Survival in Patients With Nonmetastatic Breast Cancer. JAMA Oncol 2018, 4(6):798-804.

10. Cruz-Jentoft AJ, Sayer AA: Sarcopenia. Lancet 2019, 393(10191):2636-2646.

11. Kawakami R, Murakami H, Sanada K, Tanaka N, Sawada SS, Tabata I, Higuchi M, Miyachi M: Calf circumference as a surrogate marker of muscle mass for diagnosing sarcopenia in Japanese men and women. Geriatr Gerontol Int 2015, 15(8):969-976.

12. Kawakami R, Miyachi M, Sawada SS, Torii S, Midorikawa T, Tanisawa K, Ito T, Usui C, Ishii K, Suzuki K et al: Cut-offs for calf circumference as a screening tool for low muscle mass: WASEDA'S Health Study. Geriatr Gerontol Int 2020, 20(10):943-950.

13. Barbosa-Silva TG, Bielemann RM, Gonzalez MC, Menezes AM: Prevalence of sarcopenia among community-dwelling elderly of a medium-sized South American city: results of the COMO VAl? study. J Cachexia Sarcopenia Muscle 2016, 7(2):136-143.

14. Tanaka T, Takahashi K, Akishita M, Tsuji T, lijima K: "Yubi-wakka" (finger-ring) test: A practical self-screening method for sarcopenia, and a predictor of disability and mortality among Japanese community-dwelling older adults. Geriatr Gerontol Int 2018, 18(2):224-232.

15. Hiraoka A, Izumoto H, Ueki H, Yoshino T, Aibiki T, Okudaira T, Yamago H, Suga Y, Iwasaki R, Tomida H et al: Easy surveillance of muscle volume decline in chronic liver disease patients using finger-circle (yubi-wakka) test. J Cachexia Sarcopenia Muscle 2019, 10(2):347-354.

16. Yu R, Wong M, Leung J, Lee J, Auyeung TW, Woo J: Incidence, reversibility, risk factors and the protective effect of high body mass index against sarcopenia in community-dwelling older Chinese adults. Geriatr Gerontol Int 2014, 14 Suppl 1:15-28.

17. Murakami M, Hirano H, Watanabe Y, Sakai K, Kim H, Katakura A: Relationship between chewing ability and sarcopenia in Japanese community-dwelling older adults. Geriatr Gerontol Int 2015, 15(8):1007-1012.

18. Kim H, Suzuki T, Kim M, Kojima N, Yoshida Y, Hirano H, Saito K, Iwasa H, Shimada H, Hosoi E et al: Incidence and predictors of sarcopenia onset in community-dwelling elderly Japanese women: 4-year follow-up study. J Am Med Dir Assoc 2015, 16(1):85 e81-88.

19. Petermann-Rocha F, Chen M, Gray SR, Ho FK, Pell JP, Celis-Morales C: Factors associated with sarcopenia: A cross-sectional analysis using UK Biobank. Maturitas 2020, 133:60-67.

20. Murphy RA, Ip EH, Zhang Q, Boudreau RM, Cawthon PM, Newman AB, Tylavsky FA, Visser M, Goodpaster BH, Harris TB et al: Transition to sarcopenia and determinants of transitions in older adults: a population-based study. J Gerontol A Biol Sci Med Sci 2014, 69(6):751758.

21. Pang BWJ, Wee SL, Lau LK, Jabbar KA, Seah WT, Ng DHM, Ling Tan QL, Chen KK, Jagadish MU, Ng TP: Prevalence and Associated Factors of Sarcopenia in Singaporean Adults-The Yishun Study. J Am Med Dir Assoc 2020.

22. Steff M, Bohannon RW, Petr M, Kohlikova E, Holmerova I: Relation between cigarette smoking and sarcopenia: meta-analysis. Physiol Res 2015, 64(3):419-426.

23. Dodds RM, Granic A, Robinson SM, Sayer AA: Sarcopenia, long-term conditions, and multimorbidity: findings from UK Biobank participants. J Cachexia Sarcopenia Muscle 2020, 11(1):62-68.

24. Gill TM, Baker DI, Gottschalk M, Peduzzi PN, Allore H, Byers A: A program to prevent functional decline in physically frail, elderly persons who live at home. N Engl J Med 2002, 347(14):1068-1074.

25. Dodds RM, Syddall HE, Cooper R, Benzeval M, Deary IJ, Dennison EM, Der G, Gale CR, Inskip HM, Jagger C et al: Grip strength across the life course: normative data from twelve British studies. PLoS One 2014, 9(12):e113637. 
26. e-Stat. Population (total and Japanese population), by age (single years) and sex, percentage by age, average age and median age Japan*, all shi, all gun, prefectures*, all shi of prefectures, all gun of prefectures, shi*, ku*, machi*, mura* and municipalities in 2016 [In Japanese]. Available: https://www.e-stat.go.jp/stat-search/file-download?statInfld=000031473210\&fileKind=1 [Accessed 6th November 2020].

27. Yamada Y, Nishizawa M, Uchiyama T, Kasahara Y, Shindo M, Miyachi M, Tanaka S: Developing and Validating an Age-Independent Equation Using Multi-Frequency Bioelectrical Impedance Analysis for Estimation of Appendicular Skeletal Muscle Mass and Establishing a Cutoff for Sarcopenia. Int J Environ Res Public Health 2017, 14(7).

28. Stef van Buuren, Karin Groothuis-Oudshoorn: mice: Multivariate Imputation by Chained Equations in R. Journal of Statistical Software 2011, 45(3):1-67.

29. Leong A, Dasgupta K, Chiasson JL, Rahme E: Estimating the population prevalence of diagnosed and undiagnosed diabetes. Diabetes Care 2013, 36(10):3002-3008.

30. Kim H, Hirano H, Edahiro A, Ohara Y, Watanabe Y, Kojima N, Kim M, Hosoi E, Yoshida Y, Yoshida H et al: Sarcopenia: Prevalence and associated factors based on different suggested definitions in community-dwelling older adults. Geriatr Gerontol Int 2016, 16 Suppl 1:110-122.

31. Sterne JA, White IR, Carlin JB, Spratt M, Royston P, Kenward MG, Wood AM, Carpenter JR: Multiple imputation for missing data in epidemiological and clinical research: potential and pitfalls. BMJ 2009, 338:b2393.

32. Grimes DA, Schulz KF: Uses and abuses of screening tests. Lancet 2002, 359(9309):881-884.

33. Mayhew AJ, Amog K, Phillips S, Parise G, McNicholas PD, de Souza RJ, Thabane L, Raina P: The prevalence of sarcopenia in community-dwelling older adults, an exploration of differences between studies and within definitions: a systematic review and metaanalyses. Age Ageing 2019, 48(1):48-56.

34. Moon SJ, Kim TH, Yoon SY, Chung JH, Hwang HJ: Relationship between Stage of Chronic Kidney Disease and Sarcopenia in Korean Aged 40 Years and Older Using the Korea National Health and Nutrition Examination Surveys (KNHANES IV-2, 3, and V-1, 2), $2008-2011$. PLoS One 2015, 10(6):e0130740.

35. Sui SX, Holloway-Kew KL, Hyde NK, Williams LJ, Tembo MC, Mohebbi M, Gojanovic M, Leach S, Pasco JA: Handgrip strength and muscle quality in Australian women: cross-sectional data from the Geelong Osteoporosis Study. J Cachexia Sarcopenia Muscle 2020, 11(3):690-697.

36. Kant AK, Graubard BI: Within-person comparison of eating behaviors, time of eating, and dietary intake on days with and without breakfast: NHANES 2005-2010. Am J Clin Nutr 2015, 102(3):661-670.

37. Watanabe D, Yoshida T, Nanri H, Watanabe Y, Date H, Itoi A, Goto C, Ishikawa-Takata K, Sagayama H, Ebine N et al: Association between the prevalence of frailty and doubly labeled water-calibrated energy intake among community-dwelling older adults. J Gerontol A Biol Sci Med Sci 2020.

38. Dennison EM, Sayer AA, Cooper C: Epidemiology of sarcopenia and insight into possible therapeutic targets. Nat Rev Rheumatol 2017, 13(6):340-347.

39. Baker JF, Long J, Leonard MB, Harris T, Delmonico MJ, Santanasto A, Satterfield S, Zemel B, Weber DR: Estimation of Skeletal Muscle Mass Relative to Adiposity Improves Prediction of Physical Performance and Incident Disability. J Gerontol A Biol Sci Med Sci 2018, 73(7):946-952.

40. Tang TC, Hwang AC, Liu LK, Lee WJ, Chen LY, Wu YH, Huang CY, Hung CH, Wang CJ, Lin MH et al: FNIH-defined Sarcopenia Predicts Adverse Outcomes Among Community-Dwelling Older People in Taiwan: Results From I-Lan Longitudinal Aging Study. J Gerontol A Biol Sci Med Sci 2018, 73(6):828-834.

41. Sun S, Lee H, Yim HW, Won HS, Ko YH: The impact of sarcopenia on health-related quality of life in elderly people: Korean National Health and Nutrition Examination Survey. Korean J Intern Med 2019, 34(4):877-884.

42. Newman AB, Kritchevsky SB, Guralnik JM, Cummings SR, Salive M, Kuchel GA, Schrack J, Morris MC, Weir D, Baccarelli A et al: Accelerating the Search for Interventions Aimed at Expanding the Health Span in Humans: The Role of Epidemiology. J Gerontol A Biol Sci Med Sci 2020, 75(1):77-86.

43. Dumurgier J, Elbaz A, Ducimetiere P, Tavernier B, Alperovitch A, Tzourio C: Slow walking speed and cardiovascular death in well functioning older adults: prospective cohort study. BMJ 2009, 339:b4460.

44. Newman AB, Kupelian V, Visser M, Simonsick EM, Goodpaster BH, Kritchevsky SB, Tylavsky FA, Rubin SM, Harris TB: Strength, but not muscle mass, is associated with mortality in the health, aging and body composition study cohort. J Gerontol A Biol Sci Med Sci 2006, 61(1):72-77. 
45. Volpato S, Bianchi L, Cherubini A, Landi F, Maggio M, Savino E, Bandinelli S, Ceda GP, Guralnik JM, Zuliani G et al: Prevalence and clinical correlates of sarcopenia in community-dwelling older people: application of the EWGSOP definition and diagnostic algorithm. $J$ Gerontol A Biol Sci Med Sci 2014, 69(4):438-446.

46. Fried LP, Rowe JW: Health in Aging - Past, Present, and Future. N Engl J Med 2020, 383(14):1293-1296.

47. Ikeda N, Nishi N, Miyachi M: Effects of behavioral counseling on cardiometabolic biomarkers: A longitudinal analysis of the Japanese national database. Prev Med 2018, 113:116-121.

Figures

\begin{tabular}{|c|c|c|}
\hline \multicolumn{2}{|r|}{ Settsu City } & Hannan City \\
\hline $\begin{array}{l}\text { Face to face survey } \\
\text { Recruited via their } \\
\text { participation in a specific } \\
\text { health examination } \\
\text { conducted or via Settsu's }\end{array}$ & $\begin{array}{l}\text { Mail survey }(n=10000) \\
1000 \text { subjects aged } \geq 40 \text { years stratified by } \\
\text { sex and age group from each school zone } \\
\text { (Settsu: } 10 \text { school zones } \times 1000 \text { people) }\end{array}$ & $\begin{array}{l}\text { Mail survey }(n=8000) \\
1000 \text { subjects aged } \geq 40 \text { years stratified by } \\
\text { sex and age group from each school zone } \\
\text { (Hannan: } 8 \text { school zones } \times 1000 \text { people) }\end{array}$ \\
\hline$\perp$ & & \\
\hline \multirow[t]{2}{*}{ Response: $n=525$} & Response: $n=5809(58.1 \%)$ & Response: $n=4801(60.0 \%)$ \\
\hline & \begin{tabular}{|l}
$\quad$ Excluded $(n=509)$ \\
Missing values \\
Age $(n=31)$ \\
Sex $(n=9)$ \\
Finger-circle test $(n=67)$ \\
Needed support $(n=183)$ \\
Needed long-term care $(n=219)$ \\
\end{tabular} & \begin{tabular}{|l}
\multicolumn{1}{|c}{ Excluded $(n=764)$} \\
Missing values \\
Age $(n=373)$ \\
Sex $(n=5)$ \\
Finger-circle test $(n=47)$ \\
Needed support $(n=181)$ \\
Needed long-term care $(n=158)$ \\
\end{tabular} \\
\hline Analysis: $n=525(100 \%)$ & Analysis: $n=5300(53.0 \%)$ & Analysis: $n=4037(50.5 \%)$ \\
\hline $\begin{array}{l}\text { Aim 1: to evaluate the validity } \\
\text { of finger-circle test }\end{array}$ & \multicolumn{2}{|c|}{ Aim 2: to determine the prevalence and factors associated with sarcopenia $(n=9337)$} \\
\hline
\end{tabular}

Figure 1

Flow chart of the study participants 

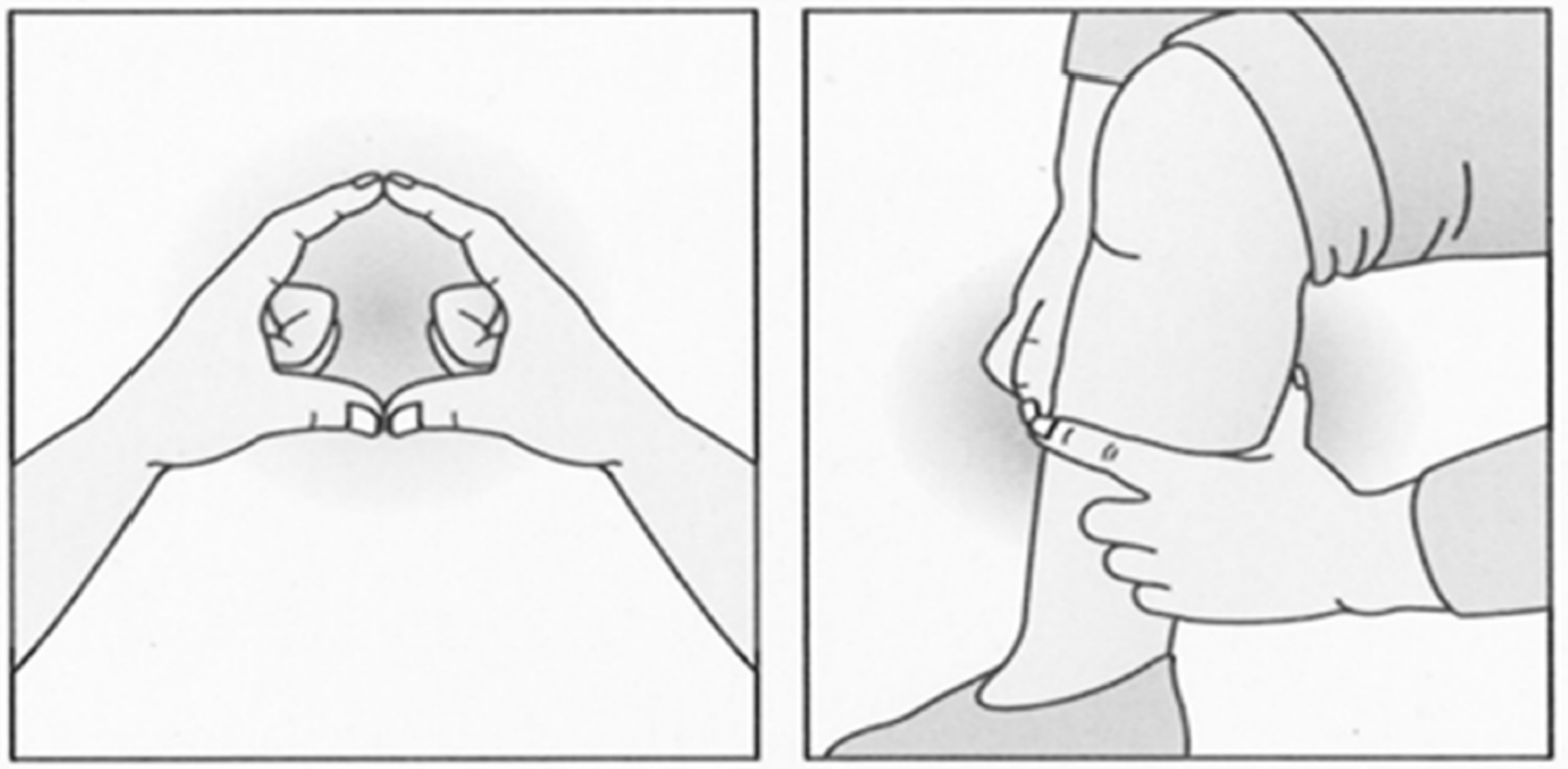

Figure 2

Finger circle (yubi-wakka) test

\section{Supplementary Files}

This is a list of supplementary files associated with this preprint. Click to download.

- Additionalfile1.docx 